This article was downloaded by: [Kungliga Tekniska Hogskola]

On: 10 J anuary 2012, At: 02:26

Publisher: Taylor \& Francis

Informa Ltd Registered in England and Wales Registered Number: 1072954 Registered

office: Mortimer House, 37-41 Mortimer Street, London W1T 3J H, UK

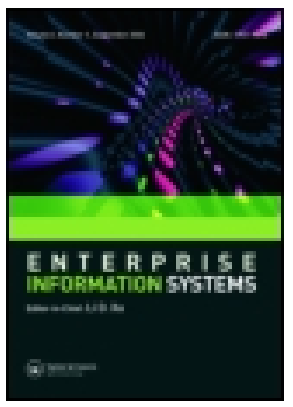

\title{
Enterprise Information Systems
}

Publication details, including instructions for authors and subscription information:

http:// www. tandfonline.com/loi/ teis20

\section{Electronic supply chain management applications by Swedish SMEs}

\author{
H. M. Beheshti ${ }^{a}$, M. Hultman ${ }^{b}$, M. -L. J ung ${ }^{b}$, R. A. Opoku ${ }^{b} \&$ E. \\ Salehi-Sangari ${ }^{b}$ \\ a Department of Management, Radford University, Radford, \\ Virginia, 24142, USA \\ ${ }^{b}$ Division of Industrial Marketing and e-Commerce, Lulea \\ University of Technology, Lulea, Sweden
}

Available online: 24 May 2007

To cite this article: H. M. Beheshti, M. Hultman, M. -L. J ung, R. A. Opoku \& E. Salehi-Sangari (2007): Electronic supply chain management applications by Swedish SMEs, Enterprise Information Systems, 1:2, 255-268

To link to this article: http:// dx.doi.org/ 10.1080/ 17517570701273221

\section{PLEASE SCROLL DOWN FOR ARTICLE}

Full terms and conditions of use: http://www.tandfonline.com/page/terms-andconditions

This article may be used for research, teaching, and private study purposes. Any substantial or systematic reproduction, redistribution, reselling, loan, sub-licensing, systematic supply, or distribution in any form to anyone is expressly forbidden.

The publisher does not give any warranty express or implied or make any representation that the contents will be complete or accurate or up to date. The accuracy of any instructions, formulae, and drug doses should be independently verified with primary sources. The publisher shall not be liable for any loss, actions, claims, proceedings, demand, or costs or damages whatsoever or howsoever caused arising directly or indirectly in connection with or arising out of the use of this material. 


\title{
Electronic supply chain management applications by Swedish SMEs
}

\author{
H. M. BEHESHTI*†, M. HULTMAN+, M.-L. JUNG ${ }^{\dagger}$, \\ R. A. OPOKU $\$$ and E. SALEHI-SANGARI† \\ $\dagger$ Department of Management, Radford University, Radford, Virginia, 24142, USA \\ \$Division of Industrial Marketing and e-Commerce, Lulea University of Technology, \\ Lulea, Sweden
}

(Received January 2007)

\begin{abstract}
The Internet has become an integral part of business activities of most corporations today. Electronic supply chain management (SCM) can improve the operational efficiency of the firm by streamlining processes between the company and its suppliers, business partners, and customers. This research explores the extent and the degree of Internet application in Swedish small- and medium-sized enterprises (SMEs). The analyses of the data show that the Swedish SMEs use the Internet in their supply chain activities to a large degree. The study establishes some differences between smaller and larger organizations as well as between manufacturing and service companies.
\end{abstract}

Keywords: Customer relationship management; Electronic business; Enterprise information systems; Enterprise resource planning; Electronic marketplace; Strategic information systems; Supply chain management; Value chain; Logistics operations; Manufacturing

\section{Introduction}

Information and communications technologies are impacting every aspect of the business enterprise at a breakneck speed. In fact, one would be hard pressed to find an organization that does not use information and communications technologies in some form or is not affected by these technologies. In many instances, the survival of the firm is at stake if technology is not used properly. Today, firms use technology to increase productivity, streamline organizations, and create electronic conglomerates.

The rapid growth of technological innovations and the fusion of information technology and electronic networks are drastically changing the way companies conduct business and remain competitive. Many business enterprises are making strategic commitments to technology for the purpose of gaining and sustaining a competitive advantage in their industry. The creation of a competitive advantage through the use of information and communications technology requires managers to use technology throughout the organization to improve information flow, reduce costs, streamline business processes, offer product variety, establish linkage with

*Corresponding author. Email: hbehesht@radford.edu 
suppliers, and to reduce response times to customer needs and expectations (Hitt and Brynjolfsson 1996, Bruce 1998).

Managers and top executives should participate in the development of enterprise-wide information systems (EIS) to include such factors as: computer hardware and software requirements and infrastructure, electronic networks, web-based business applications, electronic business, and changes to the existing systems and procedures. The development of an enterprise wide information systems plan enables managers to integrate information and communications technologies throughout the organization and link all business units together. Enterprise wide technology integration allows information users of the company to have access to the needed information in a timely fashion and make intelligent decisions.

Recent studies have examined the concept of enterprise information systems as a powerful tool for integration of systems such as: enterprise resource management (ERP), customer relationship management (CRM), knowledge management (KM), electronic business, electronic marketplace, and supply chain management (SCM) as a way of improving corporate profitability and productivity (Beheshti 2006, Chen and Li 2006, Li 2006, Li and Zhao 2006, Wang and Archer 2007).

To become more productive and profitable, firms must examine their internal as well as external processes for the creation and distribution of goods and services. The evaluation of these processes will enable the managers to access the value of activities in each process and determine how to increase the value of these activities that form a value chain from supplier to firm to distributor to customer. The effectiveness of the value chain or the supply chain depends on the degree of integration among suppliers, business partners and customers regardless of their physical location. Managing a supply chain that goes beyond the boundaries of the organization requires a sound information and communications technology infrastructure that allow corporations to use the Internet and electronic business to transcend the barriers of time and distance and take advantage of global markets and business opportunities.

The modern supply chain management concept deals with the creation of an integrated intra and inter-organizational system that is capable of sharing information, materials, and services in the value chain. Competitive advantage is created and maintained by businesses that use electronic information and communications networks to streamline production processes, reduce cycle time, improve the efficiency of procurement processes and logistics, reduce inventory costs, and improve service to customers among others.

For both manufacturing and service firms, supply-chain costs often constitute a sizeable percentage of revenue. Using an Internet-based supply chain can reduce costs and increase profit margins as well as improve the competitive advantage of the firm in the long run (Folinas et al. 2004, Handfield and Nichols 2002). The benefits of an Internet-based supply chain and its potential for improving the operations of supply chain are well documented (Deloitte and Touche 1998, Financial Times 1998, Garca-Dastugue and Lambert 2003, Johnson and Whang 2002, Lancioni et al. 2000, Rao 1999).

The Internet-based supply chain management provides opportunities for the firm to streamline the supply chain, improve speed, lower costs and to be more flexible (Lankford 2004). In addition, it can improve communications among customers 
and suppliers along with smoothing the existing flow of goods and services throughout the supply chain (Lancioni et al. 2003).

\section{Research methodology and objectives}

In Sweden, small- and medium-sized enterprises (SMEs) constitute a significant portion of the economy (Davidsson et al. 1996, NUTEK 2004). Over 99\% of all enterprises in Sweden are classified as SMEs and altogether, the SME sector accounts for $60 \%$ of total private employment. Furthermore, the SME sector represents as much as $66 \%$ of the total net investments made in Sweden (NUTEK 2004).

The main objective of this study is to determine to what extent Swedish SMEs are using the Internet in the operations and management of their supply chains and to establish a foundation for further research in this area. The major research objectives are to determine the extent of the Internet utilization in the following areas: purchasing and procurement, inventory management, transportation management, order processing, customer service, production scheduling, and interaction with vendors.

To establish a sample for the study, we used Affärsdata (www.ad.se), a Swedish national business directory. A list of companies in Sweden employing between 10 and 249 employees was generated. The list contained 27726 joint-stock SMEs. Companies with less than 10 employees, micro firms, were excluded and considered not suitable for this research and the limit of 249 conforms to the official European Commission definition of an SME (NUTEK 2004). The original list served as a sampling database from which a random sample of 1000 companies with valid e-mail addresses was chosen.

Due to funding and time limitations, a web-based self-administered survey method was chosen. According to Amit and Subhash (2005) survey methods hold the highest positions in logistics and SCM research, and by keeping it web-based it was intended to keep the data collection as quick and convenient as possible for the responding firms. The impact of electronic and web-based surveys on research cost and turnaround time, as well as efficiency and effectiveness, are significant (Kiesler and Sproull 1986, Zhang 1999).

To administer the survey, the individuals in charge of the SCM at the chosen companies were contacted by e-mail, explaining the purpose of the study and directing the recipient to the website for completion of the questionnaire. The respondents were asked to rate their use of the Internet in connection to the SCM areas in the questionnaire on a scale from 1 (no usage) to 6 (high usage). Web-based surveys generally provide low response rates (Saunders et al. 2003). For this reason, we were not surprised to receive a relatively low number of initial responses; however, after two rounds of follow-up e-mails, 97 usable responses were collected.

\section{Data analysis}

The supply chain dimensions of the collected data were analysed using multiple response and cross-tab analyses. Through median split, the data was further divided according to the number of employees. This resulted in two groups: companies between 10 and 24 employees (48.5\% of the respondents), and companies 
Table 1. Internet usage in the overall SCM decision areas.

\begin{tabular}{lcc}
\hline Application area & Percent using & Rank \\
\hline Purchasing/procurement & $80.41 \%$ & 1 \\
Inventory management & $65.98 \%$ & 4 \\
Transportation & $60.83 \%$ & 6 \\
Customer order processing & $70.10 \%$ & 3 \\
Vendor order processing & $62.89 \%$ & 5 \\
Customer service & $74.23 \%$ & 2 \\
Production scheduling & $38.14 \%$ & 7 \\
Relations with vendors & $62.89 \%$ & 5 \\
\hline
\end{tabular}

with more than 24 employees. A second broader division was made based on type of industry: service companies $(49.5 \%)$ and manufacturing $(50.5 \%)$. This division was based on the researchers' judgment and knowledge of the current Swedish industry situation. The rationale behind these sub-groupings was to investigate whether there are any correlations, or differences, between relative size or industry affiliation among the Swedish SMEs, and the use of Internet in their SCM. In order to find out if any differences in rate of usage were statistically significant, we conducted a series of $t$ tests. Initially, we intended to differentiate the companies based on annual turnover. However, because the responding firms had an annual turnover ranging from SEK 50000 to 2.7 billion, we decided to exclude this variable from the analysis.

\section{Internet applications}

The majority of the survey respondents $(91 \%)$ reported that they use the Internet in one or more decision areas of their supply chain. This is expected since according to the 2003 Information Society Index compiled by IDC/World Times (WorldPaper 2003) Sweden as a country has, over the years, maintained a top position as one of the world's strongest information technology users. In addition, the International Data Corporation (IDC) has found Sweden to be the most sophisticated nation when it comes to information technology and Internet adoption (Swedish Institute 2003). Table 1 presents the Internet usage among the responding SMEs. Data is arranged according to the most common SCM decision areas.

Clearly, the most popular application area of the Internet is purchasing/ procurement, followed by customer service, customer order processing, inventory management, vendor order processing, relations with vendors, and transportation. Production scheduling is the area that the Internet is used the least by the responding firms. The data also shows that more than $80 \%$ of the firms applied the Internet in some part of their purchasing procedures. Obviously, this high rate of usage in purchasing/procurement can be attributed to the fact that it is an important element of the day-to-day operational excellence of most firms. The availability of e-marketplaces and online shops has made it easier for companies to conduct this part of their business activities more online. Also, the second highest ranking of the customer service area is not surprising since about $75 \%$ of the Swedes use the Internet (Internet Usage in Europe 2006). 
Table 2. Internet application in purchasing/procurement.

\begin{tabular}{lcc}
\hline Purchasing/procurement applications & Percent using & Usage rate \\
\hline EDI programs with vendors in purchasing & $36.08 \%$ & 1.83 \\
On-line purchasing from vendor catalogues & $67.01 \%$ & 2.17 \\
Communicating with vendors regarding purchasing & $72.16 \%$ & 2.71 \\
Negotiating terms with vendors & $60.82 \%$ & 2.37 \\
Checking, confirming and validating price quotations of vendors & $74.23 \%$ & 2.63 \\
Arranging for returned/damaged products to vendors & $64.95 \%$ & 2.06 \\
Dealing with warranty issues of vendors & $54.64 \%$ & 1.89 \\
\hline
\end{tabular}

\section{Purchasing and the Internet}

The adoption of the Internet in the purchasing area of the supply chain has been growing in recent years (Lancioni et al. 2003). The findings support this notion and show that the Internet is widely used in this area of the supply chain in the surveyed SMEs. Table 2 shows that the Internet is utilized in a host of procurement activities such as checking, confirming and validating price quotations, communicating with vendors, online purchasing catalogues, arranging for returned/damaged goods, dealing with warranty issues and the EDI program with vendors. It is obvious that the Internet has impacted purchasing more than any other SCM decision area. Purchasing activities and negotiations can be conducted on the Internet with ease and in a timely fashion. In addition, electronic ordering, e-marketplaces, and online shopping intelligent agents such as shop and price bots have facilitated online purchasing. Communication with vendors is strongly represented here as communication requirements have been a motivating factor of Internet adoption by SMEs (Sadowski et al. 2002).

The findings also show a $65 \%$ usage of the Internet for managing product-damage/returned issues, although with a rate of usage below the median (2.06). The Internet is least applied to EDI programs with vendors and has the lowest rate of usage. Small enterprises' reluctance to join EDI communities has been addressed in previous studies (Benerjee and Golhar 1994, Iacovou et al. 1995). Although Nordic countries are leaders in e-commerce via EDI, only $6 \%$ of the companies using EDI generated $2-5 \%$ of their revenues through this medium (Swedish Institute 2003).

\section{Inventory management and the Internet}

Inventory is one of the most costly and capital intensive assets of many firms. Inventory management is considered to be the most important area of the supply chain management. Most often, inventory management systems have been characterized by unreliable control systems and the associated costs leading to excess obsolete stocks and eroding customer service levels (Ganeshan 1999, Fisher 1997, Presutti 2003, Lancioni et al. 2003). The findings in table 3 demonstrate in part that the most popular application of Internet in this decision area is the communication to customers regarding inventory rather than communication 
Table 3. Internet application in inventory management.

\begin{tabular}{lcc}
\hline Inventory management applications & Percent using & Usage rate \\
\hline $\begin{array}{l}\text { EDI programs with vendors in } \\
\quad \text { inventory management }\end{array}$ & $25.77 \%$ & 1.88 \\
$\begin{array}{l}\text { Co-ordinating JIT delivery programs to } \\
\quad \text { and from your company }\end{array}$ & $34.02 \%$ & 2.12 \\
Communicating to customers on out-of-stocks, etc. & $48.45 \%$ & 1.96 \\
Notifying customers of delays in order ship dates & $53.61 \%$ & 2.31 \\
Communicating to vendors on raw-material inventory levels & $30.93 \%$ & 2.17 \\
Communicating to customers on emergency & $35.05 \%$ & 2.12 \\
$\quad$ situations affecting inventory levels & $31.96 \%$ & 1.84 \\
Communicating to vendors on finished-goods inventory levels & $32.99 \%$ & 2.09 \\
Communicating to warehouses on inventory levels & $38.14 \%$ & 2.00 \\
Communicating to warehouses on out-of-stock & & \\
$\quad$ situations, emergencies, etc. & $42.27 \%$ & 2.44 \\
\hline Sales forecasting &
\end{tabular}

to vendors. For instance, notifying customers of delays in order shipment was rated the highest in terms of Internet usage which is preceded by communication of out-of-stocks to customers, sales forecasting, and communicating to warehouses on out-of-stocks and emergencies.

However, the rate of the Internet application in all these areas did not pass the median of 2.5. This is in contrast with previous studies conducted by Lancioni et al. (2000 and 2003) showing a high rate of usage in these areas. A simple explanation of this difference could be that previous studies dealt with large firms and this is one area that SMEs and large corporations differ in the use of the Internet. Considering the fact that EDI would be more expensive for SMEs to implement, the growth of Internet usage by companies has made it possible for smaller firms to respond to the needs of their stakeholders without the use of elaborate EDI and JIT systems.

\section{Transportation and the Internet}

The use of the Internet in transportation has grown considerably in recent years. This has resulted in the expansion of trade, significant cost savings between carriers and shippers, and improved customer service for buyers (Ellinger et al. 2003, Lancioni et al. 2003, Lasserre 2004). When dealing with information and communication intensive issues such as transportation, the utilization of the Internet can help reduce delivery time and facilitate communication among parties involved in the process (Atkinson 2001, Walker et al. 2000). The Internet has also been recognized to support the communication of scheduling pickups and drop-offs at regional distribution centres, monitoring of on-time arrivals of carriers, tracking shipments, management of claim status, and communication with carriers (Lancioni et al. 2003).

Although transport costs are high for most companies, the efficient management of transportation will enable the organization to compete better in the marketplace. The data in table 4 show that the responding SMEs are taking advantage of benefits 
Table 4. Internet application in transportation management.

\begin{tabular}{lcc}
\hline Transportation management applications & Percent using & Usage rate \\
\hline Scheduling pick-ups at distribution centres & $52.58 \%$ & 2.59 \\
Scheduling drop-offs at distribution centres & $42.27 \%$ & 2.46 \\
Monitoring on-time arrivals of carriers & $47.42 \%$ & 2.48 \\
Managing claims status and processing & $46.39 \%$ & 1.84 \\
$\quad$ communication with carriers on overall performance & & 2.21 \\
Sending out shipment notifications and tracker actions & $49.48 \%$ & \\
\hline
\end{tabular}

offered by the Internet in their transportation management with levels of usage above $42 \%$ on all the application areas.

The results reveal that the scheduling of pick-ups at distribution centres is the most popular application area. This has been facilitated by the development of Internet-based geographic information systems. The Internet enables transportation managers to make sure that the carriers they use are reliable as well as monitoring and tracking shipments to distribution centres online.

In addition, the application of the Internet provides visibility in transportation schedules thereby helping firms to inform carriers of shipment delays as they occur. Comparatively, the Internet is the least utilized when scheduling drop-offs at distribution centres showing the importance the surveyed companies place on customer service. It is also apparent that through the use of Internet tracking systems, management of claims are easily handled by SMEs.

\section{Order processing and the Internet}

Order processing has been the second most popular application of the Internet in supply chain management. The Internet brings various opportunities for improvement such as streamlining of the quotation process and lowering the overall purchasing costs to the firm (Lancioni et al. 2003, Palevich 1999).

The findings in table 5 indicate that the responding companies are using the Internet to streamline their ordering process. In terms of SCM decision areas in which the Internet has been widely applied, order processing ranks fifth. However, checking the credit status of customers is the highest Internet application area $(62.89 \%)$ ) followed by customer order processing $(59.79 \%)$. This could be due to the fact that many customers buy either with their credit cards or a cash-on-delivery basis and the companies have found a new medium to check their customers' credit status before the orders are processed. In fact, the highest Internet usage is in processing the credit status of customers (2.79). This high rate of application can be contributed to the availability of online credit check companies that can be used by SMEs to assess customers' credit rating with ease.

As mentioned earlier, one of the motivations of SMEs' adoption of the Internet is to facilitate communication with customers and vendors. Therefore, it is not surprising to find that communicating with customers on order status has the third highest (2.48) rate of usage. In relative terms, providing price quotes to customers ranks second $(60 \%)$ with usage rate of 2.72 in this decision area. 
Table 5. The Internet application in customer order processing.

\begin{tabular}{lcc}
\hline Applications & Percent using & Usage rate \\
\hline Communicating with customers on order status & $59.79 \%$ & 2.48 \\
Communicating with customers on out-of-stocks & $45.36 \%$ & 2.41 \\
Checking credit status of customers & $62.89 \%$ & 2.79 \\
Communicating with customers on returned merchandise & $46.39 \%$ & 2.27 \\
Providing total order-cycle performance for customers & $40.21 \%$ & 2.10 \\
Providing credit processing status to customers & $41.24 \%$ & 2.20 \\
Providing price quotes to customers & $59.79 \%$ & 2.72 \\
\hline
\end{tabular}

Table 6. The Internet use in vendor order processing.

\begin{tabular}{lcc}
\hline Applications & Percent using & Usage rate \\
\hline Communicating with vendors on order efforts & $53.61 \%$ & 2.12 \\
Checking credit status of vendors & $49.48 \%$ & 2.00 \\
Obtaining price quotes from vendors & $56.70 \%$ & 2.40 \\
\hline
\end{tabular}

Apart from the impact of the Internet changing the way customers' orders are processed, its ability to change how vendor orders are processed has been duly recognized in this study in terms of usage; however, not in terms of usage rate. In table 6 , it could be realized that obtaining price quotes from vendors has been affected the most by the Internet in usage terms.

By applying this medium, the highest application area by SMEs, firms can check vendors' prices online before an order is placed. Communications with vendors and checking credit status of vendors are second and third areas of application respectively. It appears that with the Internet, most of these functions are automated; the vendor can register its profiles so that buyers can easily identify their selling interest and related data such as credit status. For instance, companies such as paypal.com and payson.com are offering buyer securities online. A buyer can negotiate with suppliers and consequently buy with e-invoice with the least human involvement and assurance for protection. However, the rate of usage by the responding firms is rather low. This is one area that these companies could use more automation.

\section{Customer service and the Internet}

The availability of the Internet and affordable customer service representatives around the world has made it possible for many firms to outsource this aspect of their business in order to save costs and provide a more convenient method of service to their customers. In addition, the Internet can be utilized for customer complaints, technical service, emergency situations that may occur and affect the whole supply chain, and to sell to customers directly. 
Table 7. Internet application in customer service management.

\begin{tabular}{lcc}
\hline Applications & Percent using & Usage rate \\
\hline Receiving customer complaints & $68.04 \%$ & 2.18 \\
Providing technical service & $61.86 \%$ & 2.43 \\
Notifying customers of emergencies in the & $41.24 \%$ & 2.33 \\
$\quad$ supply chain - strikes, fires, etc. & $63.92 \%$ & 2.42 \\
Selling to customers & $36.08 \%$ & 1.94 \\
Managing the outsourcing of customer service functions & & \\
\hline
\end{tabular}

Table 8. Internet application in production scheduling.

\begin{tabular}{lcc}
\hline Applications & Percent using & Usage rate \\
\hline Co-ordinating production schedules with vendors & $35.05 \%$ & 1.74 \\
Co-ordinating production schedules with warehouses & $25.77 \%$ & 1.48 \\
$\begin{array}{l}\text { Co-ordinating production schedules with JIT schedules of vendors } \\
\text { Co-ordinating production schedules of multiple manufacturing }\end{array}$ & $26.80 \%$ & 1.50 \\
$\quad$ sites in Sweden & $21.65 \%$ & 1.76 \\
$\begin{array}{l}\text { Co-ordinating of production schedules of multiple manufacturing } \\
\text { sites at international locations }\end{array}$ & $23.71 \%$ & 1.91 \\
\hline
\end{tabular}

The results in table 7 show that the highest application area of the Internet by SMEs is managing customer complaints $(68 \%)$ and the second most popular application of the Internet in supply chains is selling to customers online. However, outsourcing of this area by the companies under study has the lowest rating. It seems that the outsourcing of customer service is not a major concern for these SMEs. However, this is an area that managers of SMEs could explore further to determine the worthiness of its application.

The advent of the Internet has provided a convenient way for customers to register their complaints to firms. This in turn has made it possible for the organizations to be more responsive to their customers through their websites and handle more contacts via the Internet.

\section{Production scheduling and the Internet}

The Internet has provided companies with the ability to expand production operations internationally while at the same time becoming more efficient. The Internet facilitates the co-ordination of production schedules and supply requirements both nationally as well as internationally and enables corporations to take advantage of low labour costs in other countries such as China, India, or the Philippines.

The findings in table 8 demonstrate that the Internet is most popular in terms of co-ordinating production schedules with vendors followed by the co-ordination of production schedules with just-in-time schedules of vendors. 
Table 9. The Internet application in vendor relations.

\begin{tabular}{lcc}
\hline Application areas & Percent using & Usage rate \\
\hline $\begin{array}{l}\text { Co-ordinating deliveries of vendors to warehouses } \\
\text { Communicating with vendors regarding raw material }\end{array}$ & $28.87 \%$ & 2.07 \\
$\quad$ stock levels at their manufacturing sites & $28.87 \%$ & 1.86 \\
Purchasing of items from vendor online catalogues/supply lists & $40.21 \%$ & 1.87 \\
$\begin{array}{l}\text { Receiving information requests from vendors } \\
\text { Providing information regarding vendor requests }\end{array}$ & $53.61 \%$ & 2.33 \\
$\begin{array}{l}\text { Providing vendors with service rating on } \\
\text { their overall performance }\end{array}$ & $30.52 \%$ & 2.06 \\
$\begin{array}{l}\text { Processing of returned materials, damaged products to vendors } \\
\text { Providing vendors with ratings of the on-time }\end{array}$ & $39.18 \%$ & 1.64 \\
$\quad$ performance of their carriers & $32.99 \%$ & 1.79 \\
\hline
\end{tabular}

Considering the fact that approximately half of our sample is comprised of service organizations, the study shows an increase in the rate of usage in this area when compared to previous studies conducted by Lancioni et al. $(2000,2003)$ and Rahman (2004).

\section{Vendor relationships and the Internet}

The establishment of a relationship and the creation of an atmosphere of collaboration as well as co-operation with vendors are essential in the effective management of the supply chain. In previous research, the Internet has proven to be an important tool in bringing suppliers and buyers together (Lancioni et al. 2000). The research findings in table 9 suggest that the Internet can help firms to improve their relationships with vendors. The use of the Internet in this application area surpasses production scheduling and transportation management.

The results show that the Internet is mostly applied in the exchange of information between the responding firms and their vendors. Receiving information from vendors had the highest percentage of use (54\%) and providing information to the vendor $(51 \%)$ had the second highest. It is noteworthy that the rate of usage was below the median value in all these application areas, the relative high rates were recorded in the two abovementioned areas. As important as it is, the least usage and frequency of usage were reported in communications with vendors regarding raw material stock levels at their manufacturing site.

\section{Levels and rate of Internet usage among different types of SMEs}

In order to create a better picture of the current industry situation, we explored how the usage and rate of usage of the Internet differed between various companies. The differentiation of companies was based on the number of employees (smaller companies, 10 to 24 employees; larger companies, 25 or more employees) and the type of industry in which the company is operating (service companies or manufacturing companies). Table 10 depicts how the level of usage differs among 
Table 10. The Internet application in the SCM by different types of companies.

\begin{tabular}{lccccc}
\hline & $\begin{array}{c}\text { All } \\
\text { companies } \\
(\%)\end{array}$ & $\begin{array}{c}\text { Smaller } \\
\text { companies } \\
(\%)\end{array}$ & $\begin{array}{c}\text { Larger } \\
\text { companies } \\
(\%)\end{array}$ & $\begin{array}{c}\text { Service } \\
\text { companies } \\
(\%)\end{array}$ & $\begin{array}{c}\text { Manufacturing } \\
\text { companies } \\
(\%)\end{array}$ \\
\hline Purchasing/procurement & 80.41 & 85.11 & 76.00 & 81.25 & 79.59 \\
Inventory management & 65.98 & 70.21 & 62.00 & 56.25 & 75.51 \\
Transportation & 60.83 & 61.70 & 60.00 & 52.08 & 69.39 \\
Customer order processing & 70.10 & 78.72 & 62.00 & 60.41 & 79.59 \\
Vendor order processing & 62.89 & 61.70 & 64.00 & 54.17 & 71.43 \\
Customer service & 74.23 & 78.72 & 70.00 & 70.83 & 77.55 \\
Production scheduling & 38.14 & 31.91 & 44.00 & 29.17 & 46.94 \\
Relations with vendors & 62.89 & 59.57 & 66.00 & 52.08 & 73.47 \\
Internet usage in & 90.72 & 97.87 & 84.00 & 87.50 & 93.88 \\
$\quad$ at least one area & & & & & \\
\hline
\end{tabular}

these categories with regard to the overall SCM decision areas as well as the overall usage of the Internet in SCM.

Some of the findings here are somewhat surprising; one would initially have expected that larger companies in general would utilize the Internet more than smaller companies; nevertheless, our findings strongly indicate that smaller companies seem to use the Internet more, both in general terms ( $98 \%$ versus $84 \%$ ) but also in most of the individual SCM application areas. Only in three application areas (vendor order processing, production scheduling, and vendor relations) do the larger companies report a higher level of usage. This might indicate that it is easier for smaller companies to adopt new technologies and that technology integration is less complex in these firms than in their larger counterparts.

The fact that manufacturing companies consistently reported higher levels of Internet usage in their SCM is not surprising. Manufacturing firms, over the years, have attempted to use technology to improve inventory management as well as the in-bound and out-bound flow of materials and goods. The only exception here is the area of purchasing/procurement where service companies reported a marginally higher level of usage ( $81 \%$ versus $80 \%$ ). The reason for this might be that many Swedish manufacturing SMEs already have established a relationship with their suppliers and a considerable portion of the purchases are still handled through simple telephone calls.

A series of $t$-tests were conducted to determine whether there were any significant differences in the rate of Internet usage in any of the SCM application areas. The rate of usage was explored in the context of company size and company industry according to the aforementioned groupings. The differences between the types of companies proved not to be statistically significant, only the results at a 0.10 level of significance and above are reported and presented in table 11.

The first general conclusion here is that, based on the number of employees and industry affiliation, there are not many significant differences in the rate of the Internet usage among the responding companies. The statistically significant differences that were established reveal that larger SMEs are more likely to arrange for returned and damaged products to vendors over the Internet than smaller SMEs $(t=1.79, p<0.1)$. A possible explanation for this is that larger companies purchase 
Table 11. Application areas with significant differences in rate of Internet usage.

\begin{tabular}{|c|c|c|c|c|c|c|}
\hline Application & Company & $N$ & Mean & $T$ & d.f. & Sig. (2-tail) \\
\hline \multirow{2}{*}{$\begin{array}{l}\text { Arranging for returned/damaged } \\
\text { products to vendors }\end{array}$} & Larger & 30 & 2.37 & \multirow[t]{2}{*}{1.788} & \multirow[t]{2}{*}{61} & \multirow{2}{*}{0.079} \\
\hline & Smaller & 33 & 1.79 & & & \\
\hline \multirow{2}{*}{$\begin{array}{l}\text { Communicating to customers } \\
\text { on emergency situations affecting } \\
\text { inventory levels }\end{array}$} & Service & 13 & 1.69 & \multirow{2}{*}{-1.748} & \multirow{2}{*}{$30.804 *$} & \multirow[t]{2}{*}{0.090} \\
\hline & manufacturing & 21 & 2.38 & & & \\
\hline $\begin{array}{l}\text { EDI programs with vendors in } \\
\text { inventory management }\end{array}$ & $\begin{array}{l}\text { Service } \\
\text { manufacturing }\end{array}$ & $\begin{array}{l}10 \\
15\end{array}$ & $\begin{array}{l}2.50 \\
1.47\end{array}$ & 2.075 & 23 & 0.049 \\
\hline $\begin{array}{l}\text { Receiving information } \\
\text { requests from vendors }\end{array}$ & $\begin{array}{l}\text { Service } \\
\text { manufacturing }\end{array}$ & $\begin{array}{l}20 \\
32\end{array}$ & $\begin{array}{l}2.80 \\
2.03\end{array}$ & 2.079 & 50 & 0.043 \\
\hline $\begin{array}{l}\text { Providing information regarding } \\
\text { vendor requests }\end{array}$ & $\begin{array}{l}\text { Service } \\
\text { manufacturing }\end{array}$ & $\begin{array}{l}20 \\
29\end{array}$ & $\begin{array}{l}2.55 \\
1.72\end{array}$ & 2.586 & 47 & 0.013 \\
\hline
\end{tabular}

*Levene's test show that equal variances are not assumed (sig. $<0.05$ ).

larger volumes which imply that they would benefit more from having a well developed return policy via the Internet. With regard to differences between industries, findings indicate that manufacturing companies are more inclined to communicate about emergency situations on their inventory levels to customers than service companies online $(t=-1.75, p<0.1)$.

However, service companies are more likely to receive information requests from vendors $(t=2.08, p<0.05)$, provide information on vendor requests $(t=2.59$, $p<0.05)$, and use the Internet in their EDI programs with vendors in inventory management than manufacturing companies $(t=2.08, p<0.05)$. The only surprising factor is in the area mentioned last. The application in question is inventory management which, one would expect, has more to do with manufacturing companies than service firms. To come to terms with this finding, a closer investigation of the data revealed that six of the responding service companies were SCM consultants. This fact, together with a relatively low number of companies using EDI $(25.8 \%)$, raised the average rate of usage among the service companies participating in the study.

\section{Conclusions}

The Internet-based supply chain management is considered to be one of the most important operations strategies for improving organizational value and effectiveness. The effectiveness of SCM depends upon the level of integration between suppliers, partners and customers that are located around the glob.

The findings of this study show that Swedish SMEs are using the Internet in several areas of their SCM in order to respond to an ever increasing global competition. These firms use the Internet in their SCM to a large extent, but the level of applications is relatively low with potential to improve the use of the Internet in all decision areas of SCM in the study. Further integration of the Internet in these areas can prove the efficiency of the operations of the SCM.

The Internet is used the most in purchasing and procurement and the least in production scheduling by surveyed companies. Production scheduling is an area in 
which managers of manufacturing firms should use the Internet more in order to take full advantage of the benefits that come with co-ordinated production schedules between the company and its vendors, warehouses, and manufacturing sites domestically as well as internationally. There are some differences between smaller and larger companies as well as manufacturing and service companies when it comes to the areas in which the Internet is used most, but there are few significant differences on the actual rate of Internet usage between different types of companies.

The results of the study have obvious relevance to SME managers planning electronic supply chain strategies. It also has relevance for supply chain management and operations managers in evaluating their SCM decision areas. The analysis can be used as a benchmark for these managers to further improve the competitive advantage of the firm. This study also demonstrates that adoption of the Internet in SCM decision areas and the frequency of usage are two sides of the same coin. Thus, after adopting the Internet in these decision areas, SME managers must make every effort to enhance the use of the Internet in these areas in order to reap the benefits of this medium.

The impact of the e-supply chain management on the competitive advantage of the firm requires more longitudinal studies to fully understand this phenomenon. Future studies can focus on the link between the Internet use in SCM and the company performance or profitability.

\section{References}

Amit, S. and Subhash, D., Review of supply chain management and logistics research. Int. J. Phys. Distrib. \& Logist. Manage., 2005, 35(9), 664-702.

Atkinson, W., How e-logistics changes shipper-carrier relationships. Logistics Management and Distribution Report, 2001, April E10-4. Available online at: http:// www.logisticsmgmt.com/article/CA74018.html (accessed 6 July 2006).

Beheshti, H.M., What managers should know about ERP/ERPII. J. Manage. Res. News, 2006, 29(4), 184-193.

Benerjee, S. and Golhar, D.Y., Electronic data interchange: characteristics of users and non-users. Inform. \& Manage., 1994, 26(1), 65-74.

Bruce, K., Can you align IT with business strategy? Strategy and Leadership, 1998, 26(5), 6-21.

Chen, Y. and Li, L., Deriving information from CRM for knowledge management-A note on a commercial bank. Syst. Res. \& Behav. Sci., 2006, 23, 141-146.

Davidsson, P., Lundmark, L. and Olofsson, C., Näringslivsdynamiken på 90-talet, 1996 (Stockholm: NUTEK).

Deloitte and Touche, Vision in manufacturing. In Global Report, Global Manufacturing Survey, 1998 (Deloitte and Touche and Deloitte Consulting: London).

Ellinger, A.E., Lynch, D.F. and Hansen, J.D., Firm size, website content, and financial performance in the transportation industry. Indust. Market. Manage., 2003, 32(3), $177-185$.

Financial Times, Digital Business Series, 1998, October-November (Prentice Hall: London, England).

Fisher, M.L., What is the right supply chain for your products? Harv. Business Rev., 1997, $\mathbf{7 5}(2), 105-116$.

Folinas, D., Manthou, V., Sigala, M. and Vlachopoulou, M., Evolution of a supply chain: cases and best practices. Internet Res., 2004, 14(4), 274-283.

Ganeshan, R., Managing supply chain inventories: a multiple retailer, one Warehouse, multiple supplier model. Int. J. Prod. Econ., 1999, 59(2), 341-354. 
Garca-Dastugue, S.J. and Lambert, D.M., Internet-enabled coordination in the supply chain. Indust. Market. Manage., 2003, 32(3), 251-263.

Handfield, R. B. and Nichols, E.L., Supply Chain Redesign: Transforming Supply Chains into Integrated Value Systems, 2002 (Financial Times/Prentice Hall: Upper Saddle River, NJ).

Hitt, L. and Brynjolfsson, E., Productivity business profitability, and consumer surplus: three different measures of information technology value. MIS Quart., 1996, 20(2), $121-142$.

Iacovou, C.L., Benbasat, I. and Dexter, A.S., Electronic data interchange and small organisations: Adoption and impact of technology. MIS Quart., 1995, 19(4), 465-485.

Internet Usage in Europe, 2006. Available online at: www.internetworldstats.com/stats4.htm (accessed 12 July 2006).

Johnson, M.E. and Whang, S., E-business and supply chain management: an overview and framework. Prod. \& Op. Manage., 2002, 11(4), 413-423.

Kiesler, S. and Sproull, L.S., Response effects in the electronic survey. Public Opinion Quart., 1986, 50(3), 402-413.

Lancioni, R.A., Smith, M.F. and Olivia, T.A., The role of the Internet in supply chain management. Indust. Market. Manage., 2000, 29(1), 45-56.

Lancioni, R.A., Smith, M.F. and Schau, H.J., Strategic Internet applications trends in supply chain management. Indust. Market. Manage., 2003, 32(3), 211-217.

Lankford, W.M., Supply chain management and the Internet. Online Inform. Rev., 2004, 28(4), 301-305.

Lasserre, F., Logistics and the Internet: transportation and location issues are crucial in the logistics chain. J. Trans. Geog., 2004, 12(1), 73-84.

Li, L., The effects of information technology implementation on supply chain collaboration. Int. J. Internet \& Enterprise Manage., 2006, 4(2), 118-134.

Li, L. and Zhao, X., Enhancing competitive edge through knowledge management in implementing ERP systems. Syst. Res. \& Behav. Sci., 2006, 23, 129-140.

NUTEK. SMEs in Sweden: Structural change and policy development, No. 002-2004, Stockholm, Sweden, 2004.

Palevich, R., Supply chain management. Hospital Mat. Manage. Quart., 1999, 20(3), 54-63.

Presutti, W.D., Supply management and e-procurement: Creating value added in the supply chain. Indust. Market. Manage., 2003, 32(3), 219-226.

Rahman, Z., Use of Internet in supply chain management: a study of Indian companies. Indust. Manage. \& Data Syst., 2004, 104(1), 31-41.

Rao, B., The Internet and the revolution in distribution: a cross-industry examination. Tech. in Soc., 1999, 21, 287-306.

Sadowski, B.M., Maitland, C. and van Dongen, J., Strategic use of the Internet by small and medium sized companies: an exploratory study. Inform. Econ. \& Policy, 2002, 14(1), 75-93.

Saunders, M., Lewis, P. and Thornhill, A., Research Methods for Business Students, 3rd ed., 2003 (Harlow: Financial Times/Prentice Hall).

Swedish Institute, Telecommunications and Information Technology in Sweden, 2003. Available online at: http://www.sweden.se/templates/cs/BasicFactsheet3693.aspx\#3 (accessed 18 January 2006).

Walker, B., Bover, D. and Martha, D., Unlocking the supply chain to build competitive advantage. Int. J. Logist. Manage., 2000, 11(2), 1-8.

Wang, S. and Archer, N., Electronic marketplace definition and classification: literature review and clarification. Ent. Inform. Syst., 2007, 1(1), 89-112.

WorldPaper, The 2003 Information Society Index, 2003. Available online at: http://www.worldpaper.com/archive/2003/october_16/october2.html (accessed 14 December 2005).

Zhang, Y., Using the Internet for survey research: a case study. J. Am. Soc. Inform. Sci., 1999, 51(1), 57-68. 